reached disease remission by physicians' assessment along with rates of $40-61 \%$ absent disease activity in PGA. Patients reported stable low level disease activity, fatigue and Auto-Inflammatory Diseases Activity Index scores (AIDAI, figure 1). CAPS was impairing social life in $50 \%$ of patients and another $50 \%$ reported days off from school/work. Lab parameters were within normal limits.

Table 1. Patient and physician assessment of clinical CAPS disease activity and laboratory markers over time.

\begin{tabular}{|c|c|c|c|c|c|c|}
\hline & \multicolumn{2}{|c|}{ Baseline } & \multicolumn{2}{|c|}{12 months } & \multicolumn{2}{|c|}{30 months } \\
\hline & $\begin{array}{l}\text { Total } \\
\text { cohort }\end{array}$ & $\begin{array}{l}\text { NOMID/ } \\
\text { CINCA }\end{array}$ & $\begin{array}{l}\text { Total } \\
\text { cohort }\end{array}$ & $\begin{array}{l}\text { NOMID/ } \\
\text { CINCA }\end{array}$ & $\begin{array}{l}\text { Total } \\
\text { cohort }\end{array}$ & $\begin{array}{l}\text { NOMID/ } \\
\text { CINCA }\end{array}$ \\
\hline Number of patients, $\mathrm{N}$ & 91 & 14 & 67 & 8 & 28 & 4 \\
\hline $\begin{array}{l}\text { Number }(\%) \text { of } \\
\text { patients with days } \\
\text { absent from work/ } \\
\text { school during } \\
\text { last } 6 \text { months }\end{array}$ & $30(34)$ & $4(29)$ & $28(42)$ & $2(25)$ & $17(61)$ & $4(100)$ \\
\hline $\begin{array}{l}\text { Number }(\%) \text { of } \\
\text { patients in } \\
\text { disease remission } \\
\text { (physician } \\
\text { assessment) }\end{array}$ & $61(68.5)$ & $11(78.6)$ & $42(66.7)$ & $4(66.7)$ & 19 (67.9) & $4(100.0)$ \\
\hline $\begin{array}{l}\text { Physician Global } \\
\text { Assessment, } \\
\text { percentage of } \\
\text { absent/mild-moder- } \\
\text { ate/severe rating, \% }\end{array}$ & $40 / 53 / 2$ & $57 / 36 / 0$ & $33 / 60 / 2$ & $33 / 50 / 0$ & $61 / 39 / 0$ & $75 / 25 / 0$ \\
\hline $\begin{array}{l}\text { Patient assessment } \\
\text { of current disease } \\
\text { activity; } 0-10, \\
\text { median (min; max) }\end{array}$ & $2.0(0 ; 7)$ & $1.0(0 ; 6)$ & $1.0(0 ; 7)$ & $1.0(0 ; 5)$ & $0.0(0 ; 7)$ & $0.0(0 ; 4)$ \\
\hline $\begin{array}{l}\text { Patient assessment } \\
\text { of current fatigue; } \\
0-10 \text {, median (min; } \\
\text { max) }\end{array}$ & $3.0(0 ; 9)$ & $2.0(0 ; 6)$ & $3.0(0 ; 8)$ & $2.0(0 ; 8)$ & $1.0(0 ; 8)$ & $4.0(0 ; 5)$ \\
\hline $\begin{array}{l}\text { Number (\%) of } \\
\text { patients without } \\
\text { impairment of } \\
\text { social life by the } \\
\text { disease }\end{array}$ & $32(52.5)$ & $4(50.0)$ & $31(62.0)$ & $3(42.9)$ & $11(47.8)$ & $1(33.3)$ \\
\hline CRP, median (mg/dl) & 0.1 & 0.2 & 0.1 & 0.5 & 0.0 & 0.2 \\
\hline & 0.3 & 0.4 & 0.5 & 0. & 0.3 & 0.1 \\
\hline ESR, median $(\mathrm{mm} / \mathrm{h})$ & 5.0 & 6.0 & 5.0 & 3.5 & 5.0 & 5.5 \\
\hline \multirow[t]{2}{*}{ SAE } & \multicolumn{3}{|c|}{ Number of events } & \multicolumn{3}{|c|}{$\begin{array}{c}\text { Incidence rate per } 100 \text { patient } \\
\text { years }\end{array}$} \\
\hline & Total cohort & NOMID/ & $/$ CINCA & Total cohort & NOMID & D/CINCA \\
\hline All types of SAE & 39 & 3 & 3 & 14.72 & & 1.72 \\
\hline SADR & $20^{\#}$ & 0 & 0 & 10.69 & & .00 \\
\hline
\end{tabular}
monia, premature delivery, skin discolouration, tonsillectomy, tonsillitis bacterial, tonsillitis streptococcal (all $\mathrm{N}=1$ event), pyrexia ( $\mathrm{N}=3$ events), not yet coded (inpatient admission, $\mathrm{N}=1$ event)CRP, c-reactive protein; ESR, erythrocyte sedimentation rate; n. a., not annotated; SAA, serum amyloid A; SADR, serious adverse drug reaction; SAE, serious adverse event

Figure 1: Median AIDAI score (0-390) of the CAPS cohort ( $\mathrm{N}=91$ at baseline) over 30 months

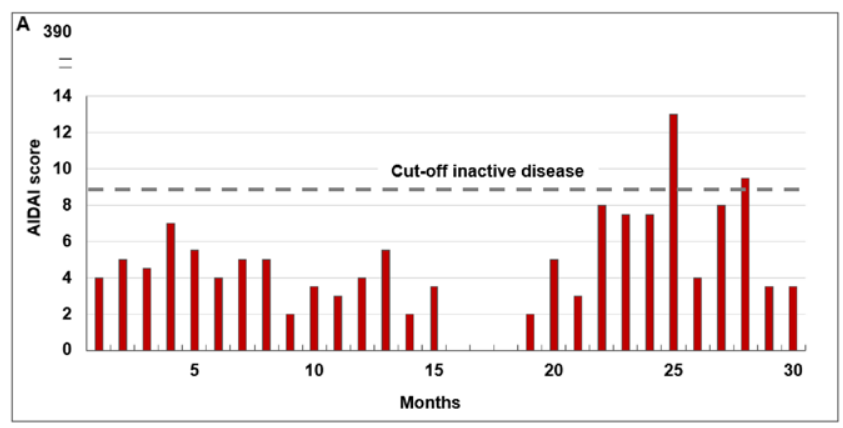

Conclusion: The 30-month interim analysis of the RELIANCE study demonstrates that long-term canakinumab treatment is safe and effective in patients with any subtype of CAPS. However, impairment of social life and days off school/work still exists. Disclosure of Interests: J. B. Kuemmerle-Deschner Consultant of: Novartis, AbbVie, Sobi, Grant/research support from: Novartis, AbbVie, Sobi, Birgit Kortus-Goetze Consultant of: Novartis, Prasad Oommen Grant/research support from: Novartis, Ales Janda: None declared, Jürgen Rech Speakers bureau: bbvie,
Biogen, BMS, Chugai, GSK, Janssen, Lilly, MSD; Mylan, Novartis, Roche, Sanofi, Sobi, UCB, Consultant of: Abbvie, Biogen, BMS, Chugai, GSK, Janssen, Lilly, MSD, Mylan, Novartis, Roche, Sanofi, Sobi, UCB, Grant/research support from: Novartis, Sobi, Tilmann Kallinich Consultant of: Sobi, Novartis, Roche, Grant/research support from: Novartis, Frank Weller-Heinemann: None declared, Gerd Horneff Speakers bureau: AbbVie, Bayer, Chugai, Merck Sharp \& Dohme, Novartis, Pfizer, Roche Grant/research support from: AbbVie, Chugai, Merck Sharp \& Dohme, Novartis Pfizer, Roche, Ivan Foeldvari Consultant of: Novartis, Catharina Schuetz: None declared, Michael Borte Grant/research support from: Pfizer, Shire, Axel Brane Consultant of: Novartis and SOBI, Julia Weber-Arden Employee of: Novartis, Norbert Blank Consultant of: Novartis, Sobi, Lilly, Pfizer, Abbvie, BMS, MSD, Actelion, UCB, Boehringer-Ingelheim, Roche, Grant/research support from: Novartis, Sobi DOI: 10.1136/annrheumdis-2021-eular.3716

\section{OP0093 RETENTION RATE OF IL-1 INHIBITORS IN PATIENTS WITH SCHNITZLER'S SYNDROME}

F. Crisafulli ${ }^{1}$, A. Vitale ${ }^{2}$, C. Gaggiano ${ }^{2}$, L. Dagna ${ }^{3}$, G. Cavalli $^{3}$, R. Cimaz ${ }^{4}$, O. Viapiana ${ }^{5}$, F. lannone ${ }^{6}$, G. Lopalco ${ }^{6}$, R. Bortolotti ${ }^{7}$, M. Abdel Jaber ${ }^{7}$, C. Montecucco ${ }^{8}$, S. Monti ${ }^{8}$, S. Balduzzi ${ }^{8}$, G. Emmi ${ }^{9}$, P. Airò ${ }^{1}$, F. Franceschini ${ }^{1}$, L. Cantarini ${ }^{2}, M$. Frassi ${ }^{1}$ on behalf of Working Group of Autoinflammatory Diseases of Italian Society of Rheumatology (SIR). ${ }^{1}$ ASST Spedali Civili and University of Brescia, Rheumatology and Clinical Immunology Unit, Brescia, Italy; ${ }^{2}$ University of Siena, Research Center of Systemic Autoinflammatory Diseases and Behçet's Disease Clinic, Department of Medical Sciences, Surgery and Neurosciences, Siena, Italy; ${ }^{3}$ Vita-Salute San Raffele University, IRCCS San Raffaele Scientific Institute, Unit of Immunology, Rheumatology, Allergy and Rare Diseases (UniRAR), Milano, Italy; ${ }^{4}$ Università degli Studi di Milano, ASST Gaetano Pini-CTO Institute, Department of Clinical Sciences and Community Health, Research Center for Adult and Pediatric Rheumatic Diseases, Division of Pediatric Rheumatology, Milano, Italy; ${ }^{5}$ University of Verona, Rheumatology Unit, Verona, Italy; ' University of Bari "Aldo Moro," Department of Emergency and Organ Transplantations, Rheumatology Unit, Bari, Italy; ${ }^{7}$ Santa Chiara Hospital, Department of Rheumatology, Trento, Italy; ${ }^{8}$ IRCCS Fondazione Policlinico San Matteo, University of Pavia, Department of Rheumatology, Pavia, Italy; ${ }^{9}$ University of Florence, Department of Experimental and Clinical Medicine, Firenze, Italy

Background: Schnitzler's syndrome is an autoinflammatory disease characterized by monoclonal gammopathy and recurrent episodes of urticaria accompanied by clinical and laboratory signs of acute inflammation. Interleukin (IL)-1 inhibitors proved to be useful in the treatment, but data on long-term safety and efficacy of these agents are sparse.

Objectives: To evaluate the retention rate of $\mathrm{IL}-1$ inhibitors in patients with Schnitzler's Syndrome.

Methods: Retrospective analysis of an Italian multicenter cohort (9 Centers). All patients fulfilled Strasbourg diagnostic criteria. Data are expressed as median [IQR] Results: We identified 15 patients ( 8 females, 7 males) who received a total of 24 treatment courses with IL-1 inhibitor treatment (16 anakinra and 8 canakinumab) between January 2001 and December 2019, with a median treatment duration of 19 months [8.5-51.3]. Median age at diagnosis was 64.0 years [56.0-72.5 and median follow up was 5.0 years $[2.0-8.0]$. Before the biological treatment, all patients were treated with corticosteroids and 11 with at least one conventional synthetic disease-modifying antirheumatic drug (csDMARD): methotrexate (5), colchicine (5), cyclosporine (3), azathioprine (1), mycophenolate mofetil (1) cyclophosphamide (1).

Fifteen patients received 16 courses of Anakinra, which was the $1^{\text {st }}$ line biological treatment in 14 patients. Seven patients continued it with benefit, while 7 patients discontinued it: 3 for secondary inefficacy; 3 for adverse events ( 2 injection site reactions, 1 severe allergic reaction); 1 for secondary inefficacy and leukopenia. Anakinra was used as $2^{\text {nd }}$ line treatment in 1 case (after tocilizumab failure); in 1 patient anakinra was resumed after temporary discontinuation and an attempt with infliximab. One patient died for multiple myeloma progression while on treatment with anakinra. The median duration of the courses with anakinra was 20.0 months [6.0-58.3]. Seven patients received 8 courses of canakinumab $(150 \mathrm{mg} / 8$ weeks in 5 cases and $150 \mathrm{mg} / 4$ weeks in 3$)$. In 5 cases the drug was administered as $2^{\text {nd }}$ line biological treatment (after anakinra failure) and in 2 cases as $3^{\text {rd }}$ line treatment ( 1 after tocilizumab and anakinra failures and 1 after anakinra and adalimumab failure). In 1 patient, it was resumed after temporary discontinuation and an attempt with etanercept. One patient died while on treatment with canakinumab due to a presumably unrelated adverse event. The median duration of canakinumab treatment courses was 19.0 months [13.5-31.0].

At last follow-up visit, all patients were on treatment with an IL-1 inhibitor: 8 with anakinra ( 7 at the dosage of $100 \mathrm{mg} /$ day, 1 at the dosage of $200 \mathrm{mg} /$ day) and 7 with canakinumab ( 2 at the dosage of $150 \mathrm{mg} / 8$ weeks, 4 at the dosage of $150 \mathrm{mg} / 4$ weeks and 1 at the dosage of $300 \mathrm{mg} / 4$ weeks). Notably, in 3 patients the dosage of canakinumab was increased since the start of the treatment. 
Among 9 patients who were on treatment with prednisone at the start of the last IL-1 inhibitor, the prednisone median dose was $12.5 \mathrm{mg} /$ day [10.0-18.8] while at the last follow-up visit it was $5.0 \mathrm{mg} /$ day $[0-7.5](p=0.02)$.

The retention rate of IL-1 inhibitors was $73.4 \%$ [SE 9.4] at 1 year and $63.6 \%$ [SE 10.4] at 2 years (Figure 1a). There was no significant difference between the retention rate of anakinra (at 1 year: $67.0 \%$ [12.2]; at 2 years: $59.6 \%$ [12.9]) and canakinumab (at 1 year: $85.7 \%$ [13.2]; at 2 years $71.4 \%$ [17.1]) (log-rank test: $\mathrm{p}=0.41$ ) (Figure 1b).
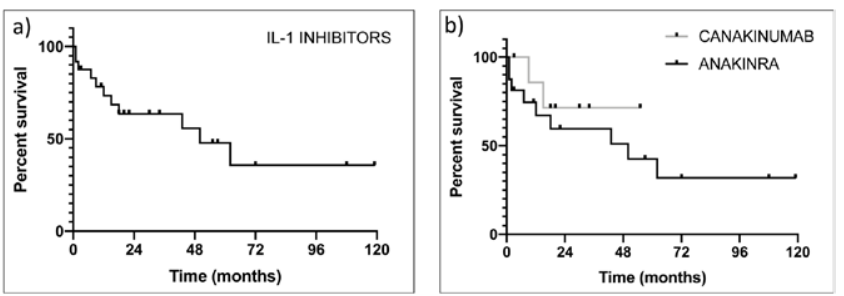

Figure 1. a) Retention rate of IL-1 inhibitors (24 courses); b) Retention rate of canakinumab ( 8 courses) and anakinra (16 courses).

Conclusion: In this multicentric cohort of patients affected by Schnitzler's syndrome, the treatment with IL- 1 inhibitors as $1^{\text {st }}, 2^{\text {nd }}$ or $3^{\text {rd }}$ line biological treatment permitted a good disease control and corticosteroid reduction in patients who did not respond to csDMARDs and/or to prior other biological DMARDs. The optimal dosage of these drugs needs to be tailored for every patient.

Acknowledgements: AIDA Network

Disclosure of Interests: Francesca Crisafulli: None declared, Antonio Vitale: None declared, Carla Gaggiano: None declared, Lorenzo Dagna: None declared, Giulio Cavalli Speakers bureau: SOBI, Novartis, Paid instructor for: SOBI, Novartis, Consultant of: SOBI, Novartis, Rolando Cimaz: None declared, Ombretta Viapiana: None declared, Florenzo lannone: None declared, Giuseppe Lopalco: None declared, Roberto Bortolotti: None declared, Masen Abdel Jaber: None declared, Carlomaurizio Montecucco: None declared, Sara Monti: None declared, Silvia Balduzzi: None declared, Giacomo Emmi: None declared, Paolo Airò: None declared, Franco Franceschini: None declared, Luca Cantarini Speakers bureau: SOBI, Novartis, Paid instructor for: SOBI, Grant/research support from: SOBI, Novartis, Micol Frassi: None declared

DOI: 10.1136/annrheumdis-2021-eular.3071

\section{OP0094 PULMONARY ARTERIAL HYPERTENSION IN ADULT- ONSET STILL'S DISEASE: A CASE SERIES OF 13 PATIENTS}

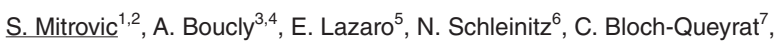
C. Christides ${ }^{8}$, J. Pouchot ${ }^{9}$, M. Humbert ${ }^{3,4,10}$, D. Montani ${ }^{3}$, L. Savale ${ }^{3}$, X. Jaïs ${ }^{3}$, O. Sitbon ${ }^{3,4}$, B. Fautrel ${ }^{11,12,13,14}$. ${ }^{1}$ Hôpital Pitié-Salpêtrière, AP-HP, Department of Rheumatology, Paris, France; ${ }^{2}$ Institut Mutualiste Montsouris, Department of Medicine, Paris, France; ${ }^{3} \mathrm{H}$ ôpital Bicêtre, AP-HP, Service de Pneumologie, Centre de Référence de l'Hypertension Pulmonaire, Paris, France; ${ }^{4}$ Université Paris-Sud, Université Paris-Saclay, INSERM Unité Mixte de Recherche en Santé S_999, Le Kremlin-Bicêtre, France; ${ }^{5} \mathrm{CHU}$ Bordeaux, Service de Médecine Interne et Maladies Infectieuses, Bordeaux, France; ${ }^{6}$ Hôpital Timone AP-HM, Service de Médecine Interne, Marseille, France; ${ }^{7}$ Hôpital Avicennes, Médecine Interne, Bobigny, France; ${ }^{8}$ Centre Hospitalier Henri Duffaut, Service de Médecine Interne, Avignon, France; ${ }^{9} \mathrm{Hôpital}$ Européen Georges Pompidou, AP-HP, Service de Médecine Interne, Paris, France; ${ }^{10}$ Université Paris-Sud, Université Paris-Saclay, Le Kremlin-Bicêtre, France; ${ }^{11}$ Hôpital Pitié-Salpêtrière, $A P$-HP, Service de Rhumatologie, Paris, France; ${ }^{12}$ Centre de Référence des Maladies Auto-Inflammatoires rares et des Amyloses, (CeRéMAIA), Paris, France; ${ }^{13}$ Pierre Louis Institute of Epidemiology and Public Health, INSERM UMR 1136, Paris, France; ${ }^{14}$ Sorbonne Université, Department of Rheumatology, Paris, France

Background: Pulmonary Arterial Hypertension (PAH) is a rare but potentially fatal complication of Adult-Onset Still's Disease (AOSD) (1). To date, only isolated observations have been published.

Objectives: To establish the largest case series of AOSD patients with $\mathrm{PAH}$, and to describe their clinical profile, evolution and response to treatments.

Methods: Cases were retrospectively identified from the French PAH network database and from an online call of the "Club Rhumatismes et Inflammation" (http://www.cri-net.com). To be included, all patients had to fulfil the Yamaguchi or Fautrel's criteria for AOSD and PAH had to be confirmed by right heart catheterization. The data were collected using a standardized questionnaire.

Results: Thirteen patients were identified. All were female, the mean age at PAH diagnosis was $32 \pm 12$ years, $2(15 \%)$ patients were Caucasian, $6(46 \%)$ from
Sub-Saharan Africa, 1 (8\%) from Asia and 4 (31\%) from West Indies. Only 2 (15\%) patients were smokers. All patients had a systemic onset of AOSD, 12 had a polycyclic and 1 a chronic articular evolution, and the mean delay between AOSD and PAH diagnosis was 2.9 (range $1.7-5.4$ ) years. At PAH diagnosis, patients were receiving the following treatments: $13(100 \%)$ corticosteroids (median dose $12 \mathrm{mg}$ [interquartile range (IQR) 9-18]), 3 (23\%) methotrexate, 8 $(61 \%)$ interleukin (IL)-1 inhibitors (exposure median duration 6.7 months [IQR 3.6-8.5]), none IL-6 inhibitors, 2 (15\%) TNF inhibitors. Six (46\%) patients developed PAH during an AOSD flare. PAH was severe at diagnosis: 2 (15\%), 7 (54\%) and $4(31 \%)$ patients were in NYHA functional class II, III and IV, respectively, with a median 6-minute walk distance of $289 \mathrm{~m}$ [IQR 0-448], a mean pulmonary arterial pressure of $41 \pm 12 \mathrm{mmHg}$, a mean pulmonary arterial occlusion pressure of $6 \pm 3 \mathrm{mmHg}$, a mean cardiac output of $3.9 \pm 1.2 \mathrm{~L} / \mathrm{min}$, a mean cardiac index of $2.5 \pm 0.9 \mathrm{~L} / \mathrm{min} / \mathrm{m}^{2}$ and a median pulmonary vascular resistance of 7 Wood Units [IQR 6-11]. The treatment prescribed after PAH diagnosis is detailed in the table. The median follow-up was 34 months [IQR 7-42]. Five patients (38.5\%) died. Figure 1 shows the overall survival. The haemodynamic response to $\mathrm{PAH}$ treatment seemed to be dissociated from the prognosis since several patients have died while their haemodynamic had improved or almost normalised.

Conclusion: PAH is a rare but potentially severe complication of AOSD, leading to death in $38.5 \%$ of our cases series. AOSD remission should be physicians' objective, since $\mathrm{PAH}$ seems to occur when the underlying disease is not controlled.

REFERENCES:

[1] Feist E, Mitrovic S, Fautrel B. Mechanisms, biomarkers and targets for adult-onset Still's disease. Nat Rev Rheumatol. 2018;1:603-618.

Table 1. Therapeutic management

\begin{tabular}{lc}
\hline Treatment & $\mathbf{n ~ ( \% )}$ \\
\hline Inotropic therapy & $5(38 \%)$ \\
HTAP treatment & $10(77 \%)$ \\
- OMonotherapy & 3 \\
- Olnitial oral dual combination therapy & 3 \\
- nDual combination therapy including intravenous (IV) prostacyclin & 1 \\
- uUpfront triple combination therapy including IV prostacyclin & 3 \\
High-dose corticosteroids & $9(69 \%)$ \\
Interleukin 1 inhibitors initiation & $2(15 \%)$ \\
Interleukin 6 inhibitors initiation & $5(38 \%)$ \\
\hline
\end{tabular}

Acknowledgements: The authors want to thank the Club Rhumatismes et Inflammation for the diffusion of the online call.

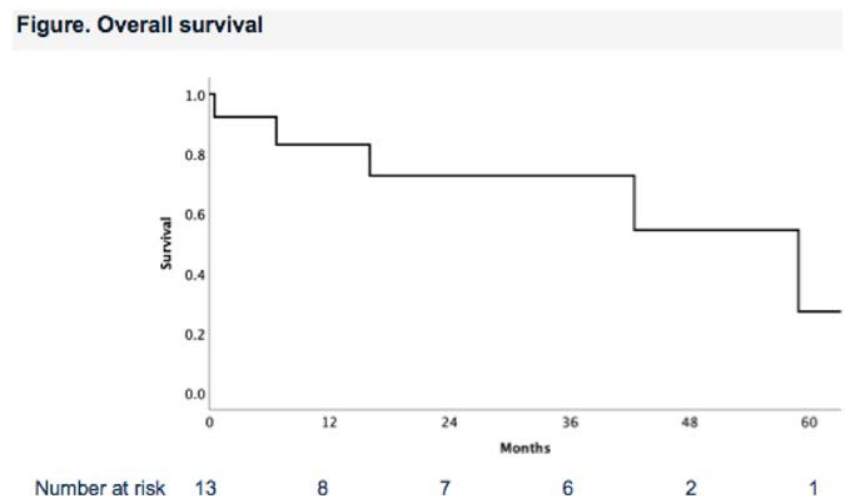

Disclosure of Interests: None declared DOI: 10.1136/annrheumdis-2021-eular.2668

\begin{tabular}{|l|l|}
\hline OP0095 & NON-GONOCOCCAL PYOGENIC ARTHRITIS OF \\
NATIVE JOINTS IN WESTERN AUSTRALIA. A \\
LONGITUDINAL POPULATION-BASED STUDY OF \\
FREQUENCY, RISK FACTORS AND OUTCOME.
\end{tabular}

J. Nossent ${ }^{1}$, W. Raymond ${ }^{1}$, D. Preen ${ }^{2}$, H. Keen ${ }^{1}$, C. Inderjeeth ${ }^{1} .{ }^{1}$ The University of Western Australia, Rheumatology, Crawley, Australia; ${ }^{2}$ The University of Western Australia, School of Population and Global Health, Crawley, Australia

Background: The worldwide incidence of PyA is reportedly rising due to a combination of increased longevity, multi- comorbidity, iatrogenic complications and increasing use of immunomodulating therapies, while there is limited data on longterm outcomes of PyA.

Objectives: To describe the recent incidence, risk factors and long-term outcomes in adults hospitalised with non-gonococcal pyogenic arthritis (PyA) of native joints in Western Australia (WA). 